\title{
IMPLEMENTASI KEBIJAKAN FISKAL: PEMBIAYAAN PROGRAM PEMBANGUNAN BERBASIS RUKUN TETANGGA(PBRT) DI KABUPATEN SUMBAWA BARAT
}

\author{
Rudi Masniadi \\ Fakultas Ekonomi Universitas Mataram
}

David Kaluge

Fakultas Ekonomi \& Bisnis Universitas Brawijaya

\begin{abstract}
Fiscal policy is one form of economic policies pursued in the context of macroeconomic stabilization, promote growth, equity, and sustainability menjega budget. West Sumbawa regency is one of regencies in NTB province has embarked on one of fiscal policy implementation is in the financing of Neighborhood-Based Development program (PBRT). PBRT program is a strategy of development by putting the region at the lowest level of development of the neighborhood (RT). This policy is the empowerment of $R T$ with the understanding that the $R T$ is not the lowest governmental structures and nongovernmental organizations that are able to understand all the complaints and needs of their citizens. RT becomes a very important institution in which is located all the pecking order and also serves as a populist economic base which is then defined as the Regulation (Regulation No. 27 Year 2008 regarding PBRT). This paper reviewed the implementation of the program PBRT is related to how big the budget from the budget for financing. Furthermore, by using Regulatory Impact Analysis will be analyzed whether the policy PBRT program will bring net benefits to society and increase welfare in West Sumbawa regency.
\end{abstract}

Keywords: fiscal policy, financing PBRT, regulatory impact analysis

\section{A. LATAR BELAKANG}

Menurut Sudibyo (2004), upaya yang perlu dilakukan untuk memulihkan perekonomian dari krisis ekonomi adalah : stabilisasi, harmonisasi, dan normalisasi kerangka besar polsoskam, stabilisasi ekonomi makro, konsolidasi fiskal menuju APBN yang berkelanjutan (sustainable), dan rekonstruksi para pemain ekonomi besar. Keberhasilan dalam stabilisasi, harmonisasi, dan normalisasi polsoskam merupakan hal pokok dalam stabilisasi dan normalisasi ekonomi, di mana kepercayaan investor dan pasar dapat dipulihkan. 
Mulai tahun 2007, pemerintah melakukan kebijakan pergeseran belanja barang ke belanja modal dan bantuan sosial untuk meningkatkan kualitas pertumbuhan ekonomi (growth with equity). Upaya mengurangi/mengentaskan masyarakat miskin akan dipercepat melalui program-program Gerakan Pembangunan Masyarakat, yaitu memperluas akses pelayanan dasar bagi masyarakat miskin, khususnya yang berada di daerah-daerah terpencil, menjaga stabilitas dan ketersediaan bahan pokok, serta membangun sistem jaminan sosial bagi masyarakat miskin (Depertemen Keuangan, 2008).

Dalam mengkaji dan mengamati peran serta masyarakat dalam pembangunan di era otonomi daerah, tentu tidak luput dengan adanya benang merah kebijakan atau strategi pembangunan yang ditempuh pemerintah setempat (Ardhana, 2010). Kabupaten Sumbawa Barat adalah salah satu kabupaten di Propinsi NTB yang menempuh kebijakan atau strategi pembangunan dengan meletakkan pembangunan pada wilayah terendah bahkan sampai pada titik nadir, yaitu pemberdayaan Rumah Tangga (RT) dengan pemahaman bahwa RT bukanlah struktur pemerintahan terendah dan merupakan lembaga swadaya masyarakat yang dapat memahami segala keluhan dan kebutuhan warganya. RT menjadi lembaga yang sangat penting yang didalamnya terletak segala tatanan kekuasaan dan juga berfungsi sebagai basis ekonomi kerakyatan. Kebijakan ini merupakan bentuk kesungguhan kebijakan Pemerintah Daerah yang Pro Poor dan Pro Growth (keberpihakan pada pemerataan dan pertumbuhan perekonomian) yang sangat relevan dengan semangat dan Pancasila sedang dibangun oleh Pemda Kabupaten Sumbawa Barat. Selain itu, hal ini tentu saja sangat relevan dengan implementasi UUD 1945 dan amanat Bung Hatta (The Founding Fathers/Bapak Koperasi Indonesia) bahwa perekonomian disusun atas usaha bersama dan dilandasi semangat kekeluargaan (Humas Pemda KSB, 2008).

Strategi/kebijakan pembangunan yang dimaksud adalah program Pembangunan Berbasiskan Rukun Tetangga atau yang dikenal dengan PBRT yang kemudian yang kemudian telah ditetapkan sebagai Peraturan Daerah (Perda No. 27 Tahun 2008 tentang PBRT). PBRT kini telah membumi di Sumbawa Barat, semakin menggema di Provinsi NTB dan kini Indonesia ingin belajar terhadap fenomenalnya program PBRT ini (Humas Pemda KSB, 2008).

Dalam implementasi dari program PBRT ini, selain memerlukan dukungan semua pihak yaitu pemerintah daerah serta seluruh komponen masyarakat, yang tidak kalah penting adalah memerlukan pengarusutamaan (mainstreaming) anggaran secara fiskal agar porsi anggaran tersebut benar-benar menyentuh masyarakat miskin secara optimal. Sehingga, perbaikan kesejahteraan dan daya beli masyarakat luas terutama kelompok miskin dapat terpenuhi secara berkelanjutan.

Dari uraian diatas, terlihat pentingnya untuk mengkaji implementasi kebijakan fiskal dalam pembiayaan program PBRT tersebut, dan menyoroti seberapa besar alokasi anggarannya. Lebih lanjut, untuk menilai apakah kebijakan ini benar-benar mampu meningkatkan kesejahteraan masyarakat secara berkelanjutan, kami menggunakan Analisis Dampak Peraturan (Regulatory Impact Analysis/RIA). Analisis ini merupakan alat penting yang digunakan untuk memastikan bahwa regulasi atau kebijakan selalu membawa manfaat bersih untuk masyarakat dalam pelaksanaan program PBRT di Kabupaten sumbawa Barat. 


\section{B. KAJIAN TEORITIS}

\section{Kebijakan Fiskal (Fiskal Policy)}

Kebijakan Fiskal adalah suatu kebijakan ekonomi dalam rangka mengarahkan kondisi perekonomian untuk menjadi lebih baik dengan jalan mengubah penerimaan dan pengeluaran pemerintah. Kebijakan ini mirip dengan kebijakan moneter untuk mengatur jumlah uang beredar, namun kebijakan fiskal lebih mekankan pada pengaturan pendapatan dan belanja pemerintah.

Instrumen kebijakan fiskal adalah penerimaan dan pengeluaran pemerintah yang berhubungan erat dengan pajak. Dari sisi pajak jelas jika mengubah tarif pajak yang berlaku akan berpengaruh pada ekonomi. Jika pajak diturunkan maka kemampuan daya beli masyarakat akan meningkat dan industri akan dapat meningkatkan jumlah output. Dan sebaliknya kenaikan pajak akan menurunkan daya beli masyarakat serta menurunkan output industri secara umum.

Kebijakan Anggaran/Politik Anggaran (Departemen Keuangan, 2008):

1. Anggaran Defisit (Defisit Budget)/Kebijakan Fiskal Ekspansif.

Anggaran defisit adalah kebijakan pemerintah untuk membuat pengeluaran lebih besar dari pemasukan negara guna memberi stimulus pada perekonomian. Umumnya sangat baik digunakan jika keaadaan ekonomi sedang resesif.

2. Anggaran Surplus (Surplus Budget)/Kebijakan Fiskal Kontraktif.

Anggaran surplus adalah kebijakan pemerintah untuk membuat pemasukannya lebih besar daripada pengeluarannya. Baiknya politik anggaran surplus dilaksanakan ketika perekonomian pada kondisi yang ekspansi yang mulai memanas (overheating) untuk menurunkan tekanan permintaan.

3. Anggaran Berimbang (Balanced Budget)

Anggaran berimbang terjadi ketika pemerintah menetapkan pengeluaran sama besar dengan pemasukan. Tujuan politik anggaran berimbang yakni terjadinya kepastian anggaran serta meningkatkan disiplin.

\section{Analisis Dampak Peraturan/Kebijakan (Regulatory Impact Analysis)}

Alat penting yang digunakan untuk memastikan bahwa regulasi selalu membawa manfaat bersih untuk masyarakat adalah Analisis Dampak Peraturan (Regulatory Impact Analysis/ RIA). Analisis memberikan suatu perkiraan/penilaian mengenai biaya dan manfaat dari sebuah usulan peraturan. RIA juga mengidentifikasi semua alternatif yang sesuai serta memberikan informasi mengenai manfaat yang dihasilkannya dibandingkan dengan usulan peraturan yang sebenarnya. RIA merupakan suatu mekanisme yang menyediakan informasi tersebut kepada masyarakat umum secara efektif. 
Sebelum sebuah proposal regulasi berdampak pada dunia bisnis dapat dipertimbangkan parlemen, maka proposal tersebut seharusnya menjalankan suatu proses peninjauan yang teliti, yaitu dengan dihasilkannya RIA. Tanggung jawab atau beban untuk membuktikan perlunya suatu regulasi ditempatkan pada kantor, badan atau departemen yang mengusulkan peraturan tersebut. Dalam cara ini semua regulasi harus dianggap "bersalah sampai terbukti tidak bersalah".

Analisa Dampak Peraturan yang digunakan didasarkan pada praktek-praktek terbaik yang telah diteliti di banyak negara di seluruh dunia, dimana analisa manfaat-biaya, telah menjadi bagian dari proses regulasi dan kebijakan selama bertahun-tahun (pernah diperkenalkan di Indonesia pada tahun 1960-1970-an di Bappenas sebagai analisis manfaat-biaya untuk evaluasi proyek).

RIA bervariasi dari satu negara ke negara lain dalam hal urutan dan penjelasan langkahlangkah. Dalam Panduan ini disajikan program RIA dengan 7 (tujuh) langkah yang diperoleh dari praktek terbaik secara internasional (Chandra, 2011) yaitu:

1. Perumusan masalah atau issue yang menimbulkan adanya kebutuhan untuk melakukan tindakan regulasi.

2. Penentuan tujuan atau sasaran dari tindakan regulasi.

3. Pemilihan alternative tindakan yang dapat dilakukan untuk mencapai tujuan.

4. Sudut pandang konsumen, pelaku bisnis, masyarakat, dan pemerintah melalui analisa biaya dan manfaat.

5. Konsultasi dengan para tenaga ahli, stakeholder dan publik.

6. Analisa masalah kepatuhan (compliance issue).

7. Penyusunan draft laporan dampak regulasi (regulatory impact statements, RIAS) yang melaporkan hasil-hasil dari RIA.

\section{Analisis Manfaat dan Biaya atas Alternatif yang Diusulkan}

Analisa manfaat dan biaya merupakan "jantung" RIA (Regulatory Impact Analysis). Informasi dan isu yang akan dianalisa sedapat mungkin disajikan atau dikonversi ke dalam bentuk kuantitatif. Upaya untuk mengkuantitatifkan isu dan informasi dengan menggunakan tolok ukur yang telah dirumuskan, tidak mudah sehingga perlu mengembangkan permasalahan maupun tujuan yang telah diidentifikasi. Oleh sebab itu, klarifikasi kedua hal tersebut merupakan bagian RIA yang sangat penting.

Untuk memulai analisa manfaat dan biaya, langkah-langkah praktis berikut sering dapat membantu, yaitu :

1. Buatlah daftar sebanyak mungkin berbagai jenis manfaat yang diperoleh dari diberlakukannya suatu peraturan.

2. Buatlah daftar sebanyak mungkin berbagai jenis biaya yang dikeluarkan sehubungan dengan diterbitkannya/ diberlakukannya suatu peraturan.

3. Lakukan konsultasi dengan tenaga ahli, stakeholder, dan masyarakat untuk menyempurnakan daftar manfaat dan biaya tersebut.

4. Siapkan sebuah tabel tentang manfaat dan biaya yang disajikan per tahun. Bagilah ke dalam kelompok sesuai dengan yang terkena dampak manfaat maupun biaya, serta gunakan "Kelompok Kunci" yang akan mewakili konsumen, pengusaha, maupun pemerintah. 


\section{HASIL DAN PEMBAHASAN}

\section{Tinjauan Umum Program PBRT}

PBRT adalah inovasi yang terlahir dari sebuah ilham dan mimpi yang kini telah menjadi kenyataan yang kemudian yang kemudian telah ditetapkan sebagai Peraturan Daerah (Perda No. 27 Tahun 2008 tentang PBRT). Program ini sedang diikhtiarkan maksimal implementasinya dalam upaya Pemerintah Daerah mewujudkan kesejahteraan masyarakat dari hari ke hari secara berkelanjutan (Konsep Sustainability Development UNDP MDGs Program). Beberapa catatan penting terhadap keberhasilan inovasi dan kebijakan ini, antara lain (Humas Pemda KSB, 2008)

1. Inovasi PBRT ini dinilai sebagai Inovasi Terbaik dalam Sayembara GLG (Good Local Governance) oleh Pemerintah Provinsi NTB yang bekerjasama dengan GTZ, salah satu NGO/LSM Internasional asal Negara Jerman pada tahun 2008.

2. Pemerintah Daerah kemudian mengusulkan kepada DPRD Kabupaten Sumbawa Barat dan menetapkannya sebagai Peraturan Daerah (Perda No. 27 Tahun 2008) tentang PBRT.

3. Yayasan Inovasi Pemerintah Daerah (YIPD) memberikan asistensi dan pendampingan terhadap keunikan PBRT yang dipadukan dengan delapan program utama yang menjadi konsensus negara-negara maju terhadap negara berkembang yang diwujudkan oleh PBB dalam Program UNDP yaitu MDGs (Millenium Development Goals) dan menghantarkan Bupati KSB mempresentasikannya di Negara Jerman dan Media Televisi Swasta Nasional Metro TV pada tahun 2009.

Pembangunan berbasis RT (Rukun Tetangga) adalah pembangunan yang meletakkan wilayah (locus) pembangunan di tingkat lingkungan sebagai basis utama pembangunan. Masyarakat RT yang merupakan unit komunitas terkecil (grass root) sebagai basis, sekaligus pelaku utama pembangunan dalam mencapai kesejahteraan sosial masyarakat.

\section{Analisis Dampak Peraturan (Regulatory Impact Analysis): Program PBRT Di Kabupaten Sumbawa Barat}

\section{Penentuan Tujuan atau Sasaran dari Tindakan Regulasi}

Menurut Mustofa (2008), secara umum Pembangunan Berbasis Rukun Tetangga (PBRT) bertujuan untuk meningkatkan kesejahteraan masyarakat. Tujuan lainnya adalah :

1. Meningkatkan dan memperluas peran serta masyarakat dalam proses pembangunan.

2. Mendorong pembangunan dan penganggaran lebih terarah pada rakyat miskin.

3. Meningkatkan ketersediaan data, informasi dan pelayanan pembangunan hingga tingkat paling bawah (RT).

4. Mendorong keterlibatan seluruh pelaku pamangku kepentingan (stakeholders) pembangunan.

5. Mendorong efisiensi dan efektifitas penganggaran daerah.

6. Mempercepat pertumbuhan (akselerasi) pembangunan mengatasi kemiskinan di daerah. 


\section{Pemilihan Alternatif Tindakan}

Untuk mencapai tujuan program PBRT, berikut ini adalah program dan komponen PBRT yang terkait langsung dengan peran dan tugas pengurus RT dalam PBRT.

Program-program PBRT (Mustofa, 2008):

\section{a. Membangun SIOS}

SIOS adalah Sistem Informasi Orang Susah, yang berisikan data dan informasi tentang keberadaan Orang Susah (warga miskin) yang ada disetiap RT. Kemiskinan dan Orang Miskin tersebut didata oleh Pengurus RT, dan ditetapkan melalui musyawarah RT yang dilakukan secara terbuka. Adapun tujuan SIOS, antara lain :

1) Sebagai alat untuk memantau perkembangan kemajuan pembangunan daerah, khususnya untuk memantau warga miskin dan kemiskinan yang berlangsung di setiap RT, termasuk Indeks Pembangunan Manusia (IPM).

2) Mendorong agar kebijakan baik berupa program maupun anggaran pembangunan daerah berorientasi/berpihak pada kelompok warga miskin.

3) Sebagai sarana untuk mengarahkan agar program pembangunan, khususnya program pengentasan kemiskinan dan bantuan terhadap warga miskin dapat tepat sasaran, terarah serta terukur.

4) Sebagai sarana untuk meningkatkan akurasi data, menghindari dan mencegah adanya manipulasi kemiskinan dan data warga miskin.

b. Membangun Perencanaan Pembangunan yang Partisipatif

Dalam membangun perencanaan pembangunan yang partisipatif, upaya yang dilakukan adalah diaplikasikan melalui Musrenbang RT. Musyawarah pembangunan berbasis RT adalah musyawarah perencanaan pembangunan daerah yang dimulai di tingkat RT atau Musrenbang RT. Kegiatan Musyawarah Rencana Pembangunan RT dilaksanakan secara partisipatif dan terbuka dengan mengedepankan kebutuhan prioritas kebutuhan warga miskin sebagai usulan dalam perencanaan pembangunan. Kegiatan ini dilaksanakan setiap tahun sebelum diselenggarakannya musyawarah rencana pembangunan desa/kelurahan (musrenbangdes/kel).

c. Memberdayakan Ekonomi Warga Miskin di Tingkat RT

Pemberdayaan ekonomi warga miskin di tingkat RT adalah sebuah program untuk meningkatkan kesejahteraan ekonomi warga miskin yang ada di tingkat RT. Program ini menitikberatkan pada bagaimana upaya mendorong lahirnya industri rumah tangga (home industry) disetiap RT dan warga miskin sebagai pelaku utama dalam industri tersebut. Misalnya, industri pembuatan tempe, industri kerajinan rotan, industri pengolahan makanan dan sebagainya. Program pemberdayaan ekonomi warga miskin untuk meningkatkan pendapatan ekonomi ditujukan agar warga miskin tersebut pada akhirnya dapat membangun ekonominya secara mandiri (Mustofa, 2008).

\section{d. Meningkatkan Partisipasi Warga Setempat}

Partisipasi adalah keterlibatan atau peran serta masyarakat dalam merencanakan, melaksanakan, dan mengawasi pembangunan yang dilaksanakan di tingkat RT, baik yang dilakukan oleh instansi pemerintah daerah, kecamatan, desa/kelurahan maupun pihak swasta. Setiap 
masyarakat berhak untuk mengetahui apa yang direncanakan, apa yang dilaksanakan dan apa yang telah dilaksanakan dalam pembangunan ini. Warga juga memiliki hak untuk mengkomplain atas hasil-hasil pembangunan yang tidak sesuai dengan apa yang merupakan kebutuhan dan kehendak warga.

Menurut Mustofa (2008), bahwa pembangunan pada hakekatnya adalah untuk warga, sehingga warga perlu berpartisipasi agar : (a) Program dan kegiatan pembangunan sesuai dengan kebutuhan warga, (b) Manfaat dan hasil program dan kegiatan pembangunan dapat dirasakan warga, (c) Meningkatkan rasa kepemilikan warga atas hasil-hasil pembangunan, (d) Para pemegang kebijakan memahami masalah dan kebutuhan warga, (e) Praktek penyalahgunaan kekuasaan dapat dicegah dan dikurangi, dan (f) Lain sebagainya.

Komponen Program PBRT (YIPD, 2008):

a. Pendampingan dan Pemberdayaan, yaitu dengan menunjuk petugas/konsultan pendamping pada setiap desa yang akan memfasilitasi dan membantu pengurus Rukun Tetangga (RT) dan kelompok kerja untuk menyusun rencana kegiatan, melaksanakan kegiatan, penatausahaan keuangan dan menggerakkan musyawarah/rembug warga RT.

b. Bantuan Stimulasi Kegiatan, yaitu untuk melaksanakan kegiatan pembangunan di lingkungan Rukun Tetangga (RT) masing-masing atau pembangunan lintas RT. Hal ini bertujuan untuk membangun partisipasi masyarakat untuk menyelesaikan masalah di lingkungannya masingmasing.

c. Pelatihan, yaitu pelatihan bagi seluruh ketua Rukun Tetangga (RT), ketua Rukun Warga (RW), kepala lingkungan dan Kepala Desa tentang teknik pembangunan partisipatif berbasis rukun tetangga. Hal ini bertujuan untuk memberikan pengetahuan dan kemampuan kepada pengurus Rukun Tetangga (RT), Rukun Warga (RW), kepala dusun/lingkungan, dan Kepala Desa.

\section{Analisis Manfaat dan Biaya Program PBRT}

\section{Identifikasi Manfaat}

Berdasarkan informasi yang didapat dari informan, maka dapat diidentifikasikan beberapa manfaat program PBRT antara lain:

a) Lebih hidupnya kembali budaya gotong royong masyarakat di Kabupaten Sumbawa Barat yang dikenal dengan sebutan "basiru” yang sudah tumbuh dan berkembang sejak berabadabad yang lalu di tengah masyarakat Sumbawa Barat.

b) Semakin terbukanya ruang dan kebebasan kepada masyarakat untuk menentukan kegiatan dan sasaran yang akan dilaksanakan oleh masyarakat disetiap RT.

c) Semakin tumbuhnya partisipasi masyarakat melalui wadah rembug/musyawarah warga yang melibatkan semua warga ditingkat Rukun Tetangga untuk ikut serta dalam perencanaan, pelaksanaan, dan pengawasan pembangunan.

d) Diterapkan manajemen terbuka yang memberikan akses kepada seluruh warga ditingkat RT untuk dapat memeriksa rencana kegiatan dan memeriksa bukti pertanggungjawaban pelaksanaan pembangunan ditingkat RT termasuk pembangunan yang dilaksanakan oleh Pemerintah Kabupaten yang berlokasi di RT. 
e) Terciptanya manajemen pembangunan yang sederhana dan modern pada tingkat RT sehingga mampu memperkuat peran kelembagaan ditingkat RT.

\section{Identifikasi Biaya}

Berdasarkan informasi yang didapat dari informan, maka dapat diidentifikasikan beberapa hal terkait pembiayaan program PBRT antara lain:

Tabel 1. Jenis-jenis dan Sumber Pembiayaan dalam Pelaksanaan program PBRT di Kabupaten sumbawa Barat

\begin{tabular}{clc}
\hline No. & \multicolumn{1}{c}{ Jenis-jenis Biaya } & Sumber \\
\hline $\mathbf{1}$ & Dana stimulus untuk koperasi RT & APBD \\
$\mathbf{2}$ & Program "Bedah Rumah" setiap RT & APBD dan Partisipasi \\
& & Masyarakat \\
$\mathbf{3}$ & Insentif untuk setiap Ketua RT (perbulan) & APBD \\
$\mathbf{4}$ & Insentif kelembagaan RT (pertahun) & APBD \\
$\mathbf{5}$ & Insentif untuk Jumantara (Juru Pantau Kesehatan & APBD \\
& Masyarakat) & APBD dan Partisipasi \\
$\mathbf{6}$ & Hadiah pada berbagai macam lomba RT & Masyarakat \\
\hline
\end{tabular}

Sumber: Humas Pemda KSB dan Hasil Wawancara Kepala Bappeda KSB

Untuk mengukur besarnya biaya yang dikeluarkan dalam implementasi program PBRT di Kabupaten Sumbawa Barat, berdasarkan hasil wawancara dengan informan, maka dapat diestimasi besar biaya seperti termuat dalam tabel berikut:

Tabel 2. Estimasi Pembiayaan Pelaksanaan Program PBRT di Kabupaten Sumbawa Barat (pertahun)

\begin{tabular}{|c|c|c|}
\hline No. & Jenis-jenis Biaya & Jumlah Biaya \\
\hline 1 & Koperasi RT : 160 unit x Rp10.000.000,- & 1.600 .000 .000 \\
\hline 2 & Bedah rumah : 720 RT x Rp5.000.000,- & 3.600 .000 .000 \\
\hline 3 & $\begin{array}{l}\text { Insentif Ketua RT : } 720 \text { RT x Rp200.000,- x } 12 \\
\text { bulan }\end{array}$ & 1.728 .000 .000 \\
\hline 4 & $\begin{array}{l}\text { Insentif Kelembagaan } \\
\text { Rp1.500.000,- }\end{array}$ & 108.000 .000 \\
\hline 5 & $\begin{array}{l}\text { Insentif Jumantara : } 720 \text { RT x Rp150.000,- x } 12 \\
\text { bulan }\end{array}$ & 1.296 .000 .000 \\
\hline 6 & $\begin{array}{c}\text { Hadiah Lomba RT Rp 100.000.000,-/tahun } \\
\text { Estimasi Biaya Pertahun = }\end{array}$ & $\begin{array}{r}100.000 .000 \\
\text { Rp 8.432.000.000 } \\
\end{array}$ \\
\hline
\end{tabular}

Sumber: Hasil wawancara (data diolah)

Berdasarkan data pada tabel 2, menunjukkan bahwa estimasi besarnya total pembiayaan dalam pelaksanaan program PBRT di Kabupaten Sumbawa Barat yang bersumber dari APBD pertahun adalah Rp 8.432.000.000,-. Pembiayaan paling besar adalah pada program "bedah rumah" yaitu sebesar Rp 3.600.000.000/tahun,-. Angka ini bisa jauh lebih besar karena di dalam perhitungannya hanya memasukkan anggaran dari APBD (Rp 5.000.000,- pertahun/RT) dan 
belum memasukkan nilai partisipasi warga (tenaga dan sumberdaya lainnya), karena dalam pelaksanaan program ini semua warga RT ikut berpartisipasi dan bergotong royong. Sedangkan pembiayaan paling kecil adalah pada program "hadiah lomba RT" Rp 100.000.000,-/pertahun. Dana untuk program ini setiap tahun dialokasikan sebagai penghargaan yang kemudian setiap tahunnya melahirkan RT Teladan, RT Beriman, RT Bebas Miras/Narkoba, RT Sehat, RT Tentram, RT Sadar Hukum, RT Bebas Teroris, RT Usaha/Produktif dan predikat lainnya.

\section{KESIMPULAN DAN REKOMENDASI}

\section{Kesimpulan}

Implementasi PBRT saat ini sedang digalakkan. Walaupun banyak sekali tantangan di lapangan namun konsep PBRT ini terus diupayakan menyentuh kebutuhan masyarakat Kabupaten Sumbawa Barat. Berdasarkan pembahasan dan analisis yang telah dilakukan maka dapat disimpulkan beberapa hal sebagai berikut :

1. Dari implementasi kebijakan fiskal dalam pembiayaan program PBRT, berdasarkan hasil Analisis Dampak Peraturan (Regulatory Analysis Impact /RIA) dapat disimpulkan bahwa sumber pembiayaan program PBRT selain dari partisipasi masyarakat, juga bersal dari alokasi APBD yaitu lebih kurang sebesar Rp 8.432.000.000,- pertahun.

2. Berdasarkan hasil Analisis Dampak Peraturan (Analysis Regulatory Impact) menunjukkan bahwa Perda Nomor 27 Tahun 2008 tentang PBRT di Kabupaten Sumbawa Barat memberikan manfaat dan nilai tambah yang besar untuk masyarakat Sumbawa Barat. Hal ini terlihat dari besarnya pembiayaan yang dialokasikan dan besarnya manfaat yang diterima masayarakat sebagai multiplyer effect dari program tersebut. Nilai tambah dan manfaat ini tidak hanya dirasakan di bidang ekonomi, tetapi juga di bidang sosial budaya dan kemasyarakatan.

\section{Rekomendasi}

Dari kesimpulan yang telah diperoleh maka dapat dikemukakan beberapa saran sebagai berikut :

1. Terkait dengan berhasilnya pelaksanaan Perda Nomor 27 tahun 2008 tentang PBRT, pemerintah perlu mengembangkan dan meningkatkan alokasi pembiayaan dalam pelaksanaan program PBRT agar nilai tambah dan multiplyer effect yang diterima masyarakat semakin besar.

2. Berjalannya program ini telah memberikan keyakinan dan pencerahan yang mendalam kepada Pemerintah Daerah dan masyarakat Kabupaten Sumbawa Barat bahwa apa yang menjadi cita-cita bersama dalam implementasi PBRT menjadi arah yang benar sekaligus menjawab kegelisahan dan lemahnya kehidupan perekonomian Bangsa Indonesia karena telah melupakan dan bahkan meninggalkan sokoguru perekonomian bangsanya yaitu koperasi itu sendiri. Oleh karena itu, harapan ke depan adalah bagaimana implementasi dari program PBRT lebih diintensivkan dan ditingkatkan. 


\section{DAFTAR PUSTAKA}

Anonymous, 2008. Makalah; Review Program Pembangunan Berbasis Rukun Tetangga. Kerjasama Pemkab KSB dan LEGITIMID KSB.Taliwang.

Anonymous, 2008. Kebijakan Moneter, Fiskal, dan Sektor Riil Dalam Rangka Penanggulangan Kemiskinan Di Indonesia. Departemen keuangan.

Anonymous, 2008. Artikel, Defenisi/Pengertian Kebijakan Fiskal \& Moneter, Instrumen Serta Penjelasannya. Depertemen Keuangan : www.google.com

Ananda, Chandra Fajri, 2011. Bahan Kuliah Ekonomi Politik di Jurusan Ilmu Ekonomi FEB UB

Anonymous, 2011. Hasil Wawancara Tentang PBRT (Via Telpon pada Tanggal 2 Juni 2011) dengan Ir.H. Amry Rakhman, M.Si (Kepala Bappeda Kab. Sumbawa Barat)/Informan Penelitian.

Ardhana, I Putu Gede, 2010. Peran Serta Masyarakat dalam Pembangunan. Denpasar : FMIPAUnud.

Humas Pemda KSB, 2010.Bumi PBRT (Website Resmi Kabupaten Sumbawa Barat. http:// subawabaratkab.co.id

Mustofa, 2008. Pembangunan Berbasis Rukun Tetangga. Kerjasama Pemkab KSB dan LEGITIMID KSB.Taliwang.

Perbup KSB, 2008. Peraturan Bupati Sumbawa Barat Nomor 11 Tahun 2008 tentang Pembangunan Berbasis Rukun Tetangga (PBRT) di Kabupaten Sumbawa Barat. Pemda KSB. Taliwang.

Sudibyo, Bambang, 2004. Stabilisasi dan Harmonisasi Perekonomian Indonesia. Makalah dalam Buku : Kebijakan Fiskal (Pemikiran, Konsep, dan Implementasi). Jakarta : Kompas

Sumbawa Barat Post, 2008. Program PBRT Merupakan Upaya Mendorong Partisipasi Masyarakat. http://sumbawabaratpost.com.

Tambunan, Tulus TH, 2001. Perekonomian Indonesia (Teori dan Temuan Empiris).Jakarta : Ghalia Indonesia

YIPD KSB, 2008.Pedoman Juklak dan JuknisProgram Pembangunan Berbasis Rukun Tetangga Kabupaten Sumbawa Barat. Yayasan Inovasi Pemerintahan Daerah (YIPD) KSB. Taliwang. 